\title{
Is pulmonary vein isolation effective for permanent atrial fibrillation?
}

\author{
Yosuke Ishii, MD
}

Received: 10 June 2011

(C) The Japanese Association for Thoracic Surgery 2012

Recently, various surgical ablation devices have been developed to simplify the maze procedure. Pulmonary vein isolation with no atrial incisions has become feasible using these ablation devices. Focal activation arising from the pulmonary veins is one of the mechanisms underlying atrial fibrillation (AF), and pulmonary vein isolation is effective for curing AF caused by this mechanism. It has been reported that the pulmonary veins are an important source of paroxysmal AF. ${ }^{1}$ Electrophysiological studies revealed that approximately $90 \%$ of the ectopic foci originated from the pulmonary veins in patients with paroxysmal AF.

The mechanisms of AF are complicated. There are two major electrophysiological mechanisms that may participate in its initiation and perpetuation. In the case of the first mechanism, arrhythmogenic activity that originates in the muscle sleeves of the pulmonary veins may trigger and maintain AF, particularly paroxysmal AF. Such a primary driver can induce other secondary drivers, and AF may be perpetuated by the secondary drivers even if the primary driver terminates. High, frequent reentrant circuits or rotors can act as drivers of $\mathrm{AF}$ and are seen in the pulmonary veins or posterior left atrium during $\mathrm{AF}^{2}$ With this mechanism, $\mathrm{AF}$ can be cured by isolating the drivers in the pulmonary veins or

This editorial refers to the article by Takasaki et al. on pp. 82-89 of this issue of General Thoracic and Cardiovascular Surgery.

Y. Ishii $(\bowtie)$

Department of Cardiovascular Surgery, Nippon Medical School Chiba Hokusoh Hospital, 1715 Kamakari, Inzai, Chiba

270-1694, Japan

Tel. +81-476-99-1835; Fax +81-476-99-1921

e-mail: yosuke-i@nms.ac.jp posterior left atrium. The second other major mechanism is multiple wavelet reentry. It has been suggested that $\mathrm{AF}$ is the result of the random propagation of multiple wavelets across the atria. Based on the theory behind this mechanism, curing AF requires interrupting multiple changing circuits with linear atrial incisions. ${ }^{3-5}$

The article by Takasaki et al. demonstrated that the cryo-maze procedure was more effective in eliminating permanent AF associated with both mitral and tricuspid valve disease than was box pulmonary vein isolation. ${ }^{6}$ It also warned against incomplete ablation, which was shown to cause postoperative atrial tachycardia. The mechanisms of AF are different in paroxysmal and permanent AF. Whereas the most common cause of paroxysmal AF is focal activation arising from the pulmonary veins, the cause of permanent AF is not just simply focal activation arising from the pulmonary veins but also macro-reentry around the right or left atrium. Particularly in the case of permanent AF patients with both mitral and tricuspid valve disease, the atrial wall often shows greater hypertrophy of cardiomyocytes or more intercellular fibrosis than that of patients in sinus rhythm. ${ }^{7}$ This difference results in inhomogeneous conduction. Inhomogeneous conduction around the right or left atrium participates in developing permanent AF. Therefore, in addition to pulmonary vein isolation, biatrial incisions are also needed to cure permanent AF.

Regarding outcomes from surgical therapy, it has been noted that pulmonary vein isolation was more effective for paroxysmal AF than for permanent AF. The AF cure ratio of pulmonary vein isolation was reported to be approximately $70 \%-80 \%$ for paroxysmal AF and $50 \%-60 \%$ for permanent $A F^{8-12}$ These results suggest that focal activation arising from the pulmonary veins must be a major cause of paroxysmal AF. On the 
other hand, the full-maze procedure, which utilizes bilateral atrial incisions and pulmonary vein isolation, has been known to be effective for all types of AF, including permanent AF. ${ }^{13-15}$ In patients with mitral and tricuspid valve disease, intraoperative mapping has shown that focal activation from the pulmonary veins and macroreentry around the right or left atrial free wall occur simultaneously during permanent AF. ${ }^{16}$ In these patients, pulmonary vein isolation alone fails to cure AF because of the macro-reentry around the right or left atrium. ${ }^{9}$ Moreover, some permanent AF cases have repetitive activations arising from the posterior left atrium between the right and left pulmonary veins. ${ }^{16}$ Pulmonary vein isolation cannot cure this type of AF (nonpulmonary vein focus). In such cases, box pulmonary vein isolation described in the present article is needed to address the focal activation arising from the posterior left atrium. ${ }^{6}$ It has been shown that isolating the entire posterior left atrium by creating a box lesion is more effective in eliminating AF than a single connecting lesion between the right and left pulmonary veins. ${ }^{17,18}$ Therefore, surgical procedures should be chosen after careful consideration of the individual mechanism of AF.

If we use surgical ablation devices instead of the "cut and sew" technique, it is important to avoid incomplete ablation lesions. The "cut-and-sew" technique can completely prevent propagation of abnormal activation and interrupt reentrant circuits. However, ablation devices, including traditional cryoablation and radiofrequency ablation, do not necessarily guarantee transmural and continuous necrosis. ${ }^{19,20}$ Because focal activations that originate from the pulmonary veins are thought to trigger and maintain $\mathrm{AF}$, complete pulmonary vein isolation is essential to successful AF surgery. It is necessary to confirm complete conduction block when performing pulmonary vein isolation by pacing from the pulmonary veins during beating heart surgery. If pulmonary vein pacing shows that pulmonary vein isolation was incomplete, then additional applications of ablation energy are required to achieve complete conduction block during surgery. Moreover, in clinical and experimental studies, it has been noted that a nontransmural ablation lesion causes a conduction gap on the mitral or tricuspid annulus, resulting in atrial reentrant tachycardia after surgery. ${ }^{6,21-23}$ A small amount of viable myocardium can propagate across the ablation lesion with slow conduction. This slow conduction in the reentrant circuit causes stable reentrant activation, which allows atrial reentrant tachycardia to occur. Takasaki et al. also described incomplete ablation of the pulmonary veins, or the mitral and tricuspid annuli created recurrence of $\mathrm{AF}$ or atrial tachycardia after surgery, resulting in a low AF cure ratio. ${ }^{6}$ Taking care to create complete conduc- tion block in all ablation lesions can improve the AF cure ratio after surgery no matter which surgical procedures are performed to cure AF.

\section{References}

1. Haissaguerre M, Jais P, Shah DC, Takahashi A, Hocini M, Quiniou G, et al. Spontaneous initiation of atrial fibrillation by ectopic beats originating in the pulmonary veins. $\mathrm{N}$ Engl $\mathbf{J}$ Med 1998;339:659-66.

2. Jalife J. Rotors and spiral waves in atrial fibrillation. J Cardiovasc Electrophysiol 2003;14:776-80.

3. Cox JL, Schuessler RB, D’Agostino HJ Jr, Stone CM, Chang $\mathrm{BC}$, Cain ME, et al. The surgical treatment of atrial fibrillation. III. Development of a definitive surgical procedure. J Thorac Cardiovasc Surg 1991;101:569-83.

4. Cox JL, Schuessler RB, Lappas DG, Boineau JP. An 8 1/2year clinical experience with surgery for atrial fibrillation. Ann Surg 1996;224:267-73.

5. De Groot NM, Houben RP, Smeets JL, Boersma E, Schotten $\mathrm{U}$, Schalij MJ, et al. Electropathological substrate of longstanding persistent atrial fibrillation in patients with structural heart disease: epicardial breakthrough. Circulation 2010; 122:1674-82.

6. Takasaki T, Sueda T, Imai K, Orihashi K, Takahashi S, Kurosaki T, et al. Mid-term results of the box pulmonary vein isolation and the cryo-maze procedure for chronic atrial fibrillation associated with mitral valve disease. Gen Thorac Cardiovasc Surg 2011.

7. Saito T, Tamura K, Uchida D, Saito T, Togashi M, Nitta T, et al. Histopathological features of the resected left atrial appendage as predictors of recurrence after surgery for atrial fibrillation in valvular heart disease. Circ J 2007;71:70-8.

8. Edgerton JR, McClelland JH, Duke D, Gerdisch MW, Steinberg $\mathrm{BM}$, Bronleewe $\mathrm{SH}$, et al. Minimally invasive surgical ablation of atrial fibrillation: six-month results. J Thorac Cardiovasc Surg 2009;138:109-13.

9. McCarthy PM, Kruse J, Shalli S, Ilkhanoff L, Goldberger JJ, Kadish $\mathrm{AH}$, et al. Where does atrial fibrillation surgery fail? Implications for increasing effectiveness of ablation. $\mathbf{J}$ Thorac Cardiovasc Surg 2010;139:860-7.

10. Han FT, Kasirajan V, Kowalski M, Kiser R, Wolfe L, Kalahasty $\mathrm{G}$, et al. Results of a minimally invasive surgical pulmonary vein isolation and ganglionic plexi ablation for atrial fibrillation: single-center experience with 12-month follow-up. Circulation 2009;2:370-7.

11. Bagge L, Blomstrom P, Nilsson L, Einarsson GM, Jideus L, Blomstrom-Lundqvist C. Epicardial off-pump pulmonary vein isolation and vagal denervation improve long-term outcome and quality of life in patients with atrial fibrillation. J Thorac Cardiovasc Surg 2009;137:1265-71.

12. Beyer E, Lee R, Lam BK. Point: minimally invasive bipolar radiofrequency ablation of lone atrial fibrillation: early multicenter results. J Thorac Cardiovasc Surg 2009;137:521-6.

13. Damiano RJ Jr, Schwartz FH, Bailey MS, Maniar HS, Munfakh NA, Moon MR, et al. The Cox maze IV procedure: predictors of late recurrence. J Thorac Cardiovasc Surg 2011;141:113-21.

14. Prasad SM, Maniar H, Camillo CJ, Schuessler RB, Boineau JP, Sundt TM 3rd, et al. The Cox-maze III procedure for atrial fibrillation: long-term efficacy in patients undergoing lone versus concomitant procedures. J Thorac Cardiovasc Surg 2003;126:1822-7. 
15. Fujita T, Kobayashi J, Toda K, Nakajima H, Iba Y, Shimahara $\mathrm{Y}$, et al. Long-term outcome of combined valve repair and maze procedure for nonrheumatic mitral regurgitation. $\mathrm{J}$ Thorac Cardiovasc Surg 2010;140:1332-7.

16. Nitta T, Ohmori H, Sakamoto S, Miyagi Y, Kanno S, Shimizu K. Map-guided surgery for atrial fibrillation. J Thorac Cardiovasc Surg 2005;129:291-9.

17. Lall SC, Melby SJ, Voeller RK, Zierer A, Bailey MS, Guthrie TJ, et al. The effect of ablation technology on surgical outcomes after the Cox-maze procedure: a propensity analysis. J Thorac Cardiovasc Surg 2007;133:389-96.

18. Voeller RK, Bailey MS, Zierer A, Lall SC, Sakamoto S, Aubuchon $\mathrm{K}$, et al. Isolating the entire posterior left atrium improves surgical outcomes after the Cox maze procedure. J Thorac Cardiovasc Surg 2008;135:870-7.

19. Melby SJ, Zierer A, Kaiser SP, Schuessler RB, Damiano RJ Jr. Epicardial microwave ablation on the beating heart for atrial fibrillation: the dependency of lesion depth on cardiac output. J Thorac Cardiovasc Surg 2006;132:355-60.

20. Lustgarten DL, Keane D, Ruskin J. Cryothermal ablation: mechanism of tissue injury and current experience in the treament of tachyarrhythmias. Prog Cardiovasc Dis 1999;41:48198.

21. Scharf C, Oral H, Chugh A, Hall B, Good E, Cheung P, et al. Acute effects of left atrial radiofrequency ablation on atrial fibrillation. J Cardiovasc Electrophysiol 2004;15:515-21.

22. Shah D, Haissaguerre M, Takahashi A, Jais P, Hocini M, Clementy J. High-density mapping of activation through an incomplete isthmus ablation line. Circulation 1999;99: 211-5.

23. Ishii Y, Nitta T, Kambe M, Kurita J, Ochi M, Miyauchi Y, et al. Intraoperative verification of conduction block in atrial fibrillation surgery. J Thorac Cardiovasc Surg 2008;136:9981004. 